San Jose State University

SJSU ScholarWorks

Master's Theses

Master's Theses and Graduate Research

Summer 2014

\title{
The Influence of Socioeconomic Factors on the Development of Early Number Concepts
}

Brittany Meghan Caldwell

San Jose State University

Follow this and additional works at: https://scholarworks.sjsu.edu/etd_theses

\section{Recommended Citation}

Caldwell, Brittany Meghan, "The Influence of Socioeconomic Factors on the Development of Early Number Concepts" (2014). Master's Theses. 4453.

DOI: https://doi.org/10.31979/etd.8dnf-pf6y

https://scholarworks.sjsu.edu/etd_theses/4453

This Thesis is brought to you for free and open access by the Master's Theses and Graduate Research at SJSU ScholarWorks. It has been accepted for inclusion in Master's Theses by an authorized administrator of SJSU ScholarWorks. For more information, please contact scholarworks@sjsu.edu. 


\title{
THE INFLUENCE OF SOCIOECONOMIC FACTORS ON THE DEVELOPMENT OF EARLY NUMBER CONCEPTS
}

\author{
A Thesis \\ Presented to \\ The Faculty of the Department of Child and Adolescent Development \\ San José State University \\ In Partial Fulfillment \\ of the Requirements for the Degree \\ Master of Arts \\ by \\ Brittany Caldwell \\ September 2014
}


(C) 2014

Brittany M. Caldwell

ALL RIGHTS RESERVED 
The Designated Thesis Committee Approves the Thesis Titled

THE INFLUENCE OF SOCIOECONOMIC FACTORS ON THE DEVELOPMENT OF EARLY NUMBER CONCEPTS

by

Brittany M. Caldwell

\begin{abstract}
APPROVED FOR THE DEPARTMENT OF CHILD AND ADOLESCENT
DEVELOPMENT
\end{abstract}

SAN JOSÉ STATE UNIVERSITY

May 2014
Dr. Emily Slusser
Department of Child and Adolescent Development
Dr. Nadia Sorkhabi
Department of Child and Adolescent Development
Dr. John Jabagchourian
Department of Child and Adolescent Development 


\title{
ABSTRACT \\ THE INFLUENCE OF SOCIOECONOMIC FACTORS ON THE DEVELOPMENT OF EARLY NUMBER CONCEPTS
}

\author{
by Brittany M. Caldwell
}

Why are some children entering school unable to count, while others are able to do simple addition? It may be that early experiences, like practice with numbers and extra resources to promote logical thinking, lay the foundation for how children and adults understand and use math in their everyday lives. The major objectives of this thesis are to explore the 1) link between children's intuitive number sense and their development of exact number concepts, 2) influence of language on early math achievement, and 3) influence of socioeconomic factors on various aspects of cognitive development. Participants included 133 preschool aged children from San José, California, and Middletown, Connecticut. Children's development was assessed in three areas: number language, number sense, and general vocabulary. After completion of the tasks, demographic information, such as family income and education, was collected through surveys sent home to parents. Results show that parent income is related to children's general vocabulary but not related to number language or number sense. General vocabulary is also linked to children's number language, with evidence that the relationship between number sense and general vocabulary is mediated by children's number language. 


\section{ACKNOWLEDGEMENTS}

First and foremost I would like to thank my advisor and mentor, Dr. Emily Slusser for all of her time and support throughout my master's program and the completion of my thesis project. Her passion and dedication to the field of education and to research fueled my motivation for this study. Dr. Slusser spent endless hours with me coding and assessing data and her expertise helped me develop a better understanding of the topic. I express much gratitude to all the Dr. Slusser has done in preparation and completion of this work.

Second, I would like to thank my family and friends who supported and helped me along the way. It is these people who have reminded me that there are things in life other than school and work that kept me going during the difficult times. It is also these people who pushed me to strive for more education, propelling me toward the next step, namely a doctoral degree. Therefore, I thank my family and my friends tremendously.

Third, I would like to express gratitude to Dr. Nadia Sorkahbi and Dr. John Jabagchourian, in addition to Dr. Slusser, for participating on my thesis committee. Their critique and questions helped me to consolidate and improve the final work. They provided different points of view that contributed to the quality of this study.

Finally, I would like to thank the entire faculty, staff, and the 2014 master's cohort in the Child and Adolescent Development Department. I gained connections and knowledge by knowing all of these people. Truly, it is the people we know in life that help us become who we are. 


\section{TABLE OF CONTENTS}

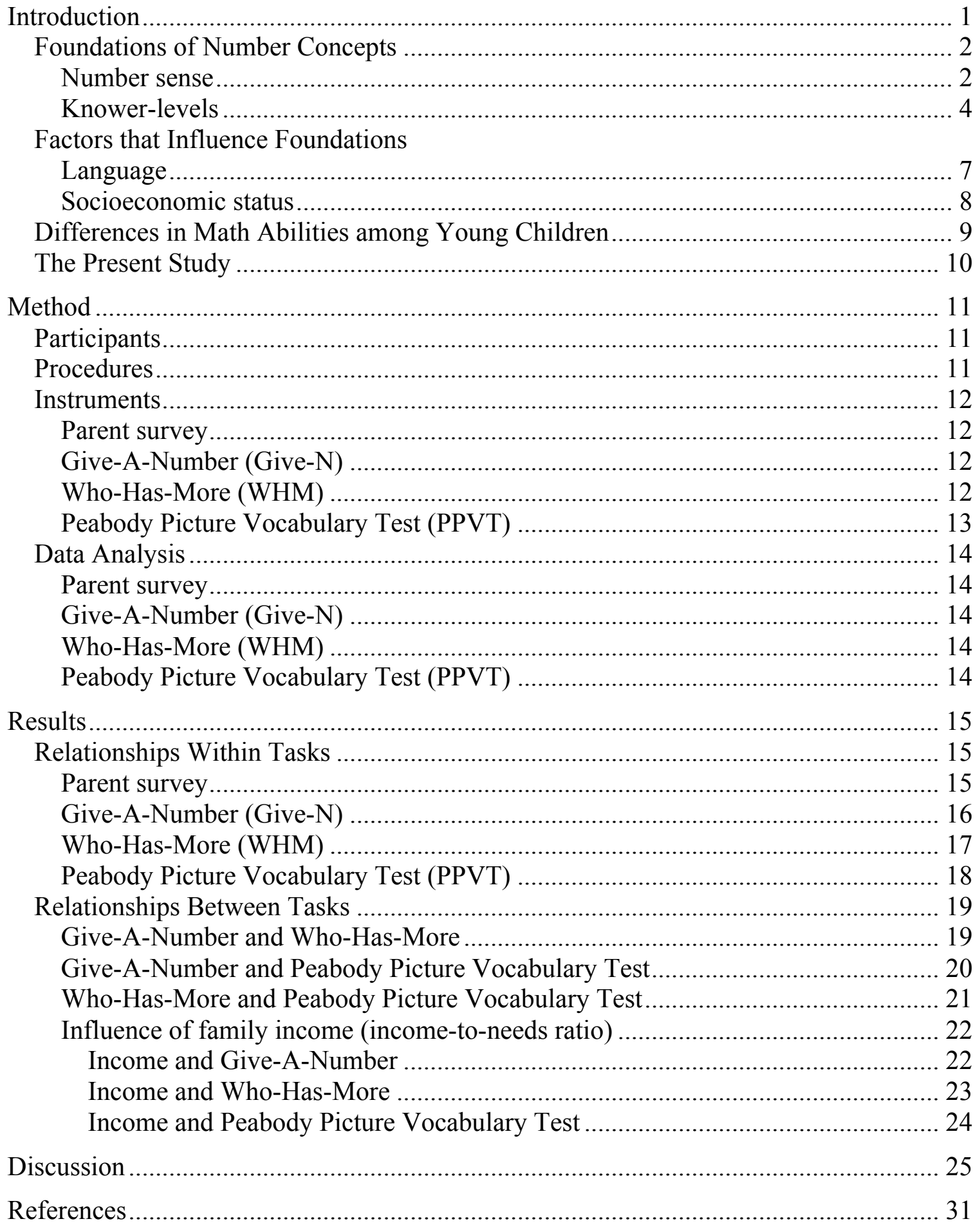




\section{LIST OF FIGURES}

Figure 1 Distribution of family income (Figure 1A) and education

(Figure 1B) 15

Figure 2 Children's number word knowledge (i.e., knower-level,

determined through the Give-N task) systematically increases with age 17

Figure 3 Children's numerical acuity (as measured by their performance

on the WHM task) systematically increases with age 18

Figure 4 Children's general vocabulary (as measured by the PPVT) approximates a normal distribution

Figure 5 Children's numerical acuity (performance on the WHM task)

is systematically related to their number word knowledge (knower-level)

Figure 6 Children's general vocabulary (PPVT score) is systematically

related to their number word knowledge (knower-level) 21

Figure 7 Children's numerical acuity (performance on the WHM task) is systematically related to their general vocabulary (PPVT score)

Figure 8 Socioeconomic status is not systematically related to children's

number word knowledge (as measured by the Give-N task)

Figure 9 Socioeconomic status is not systematically related to children's

numerical acuity (as measured by the WHM task) 
Figure 10 Socioeconomic status is systematically related to children's general vocabulary skills (as measured by the PPVT task) ……………………............ 25 


\section{Introduction}

Although it is not always apparent, adults and children use mathematical thinking on a daily basis (e.g., Will I have enough money for this new shirt? How much sugar do I need for these cookies?). Even though many people believe that they simply are not "good at math," math influences much of what we do. In fact, recent research reveals a strong connection between early math abilities and later academic success (Duncan et al., 2007; Romano, Babchishin, Pagani, \& Kohen, 2010). Using data from six longitudinal studies, Duncan and his colleagues (2007) discovered that mathematical understanding at school entry (5-6 years old) is even more predictive of academic success in later elementary and middle school than other skills, including language and literacy (see also Romano et al., 2010).

Despite these findings, it seems that the importance of early math is not as well recognized as the importance of literacy. This is demonstrated by the fact that parents are often encouraged to read a book with their child on a daily basis but are rarely encouraged to do math problems. Even with this lack of attention to math in the home, researchers have been investigating the development of early math and number concepts for a long time (e.g., Baroody \& Price, 1983; Carey, 2009; Duncan et al., 2007; Gallistel \& Gelman, 2000; Halberda \& Feigenson, 2008; Wynn, 1990; 1992). This line of research has shown that practice and guidance with numbers and number concepts can increase these early math abilities (Baroody \& Price, 1983; Halberda \& Feigenson, 2008). Additionally, certain skills, such as the ability to count, are more dependent on experience than are more complex understandings of number, such as the cardinal 
principle of counting (Dowker, 2008). Yet to better understand the influence of external factors, such as practice with numbers or family income, it is important to first know how a conceptual understanding of number develops as well as how this establishes the groundwork for more advanced mathematical thinking.

\section{Foundations of Number Concepts}

Number Sense. While researchers have recently gained much insight into the development of early number concepts, it is increasingly important to explore how children's development is influenced by external factors like experience or income. Some of the differences that are observed in children's math abilities as they enter school (e.g., a child's ability to count or correctly produce a specific quantity of items) can be attributed to knowledge and experiences that are formed in the preschool years. One math ability in which variation is particularly evident prior to formal education is children's "number sense." Number sense is an individual's intuitive understanding of number and quantity (Dehaene, 1997) and is said to be supported by the Approximate Number System (ANS) (Gelman \& Gallistel, 1978). The acuity of this system is then predictive of the quality of one's number sense (e.g., Halberda \& Feigenson, 2008).

Although it is argued that number sense seems to exist in all humans during infancy (Gelman \& Gallistel, 1978), it is not fully developed in young children. Halberda and Feigenson (2008) investigated the developmental trajectory of number sense for preschool children and found that children between ages 3 and 6 are still developing their number sense and that it does not reach full capacity until adolescence. 
One way to evaluate number sense is through a simple numerical discrimination task (e.g., Halberda \& Feigenson, 2008). For this task, a participant is presented with a display of two sets of dots and is asked, "Which array has more dots?" Responses are then used to establish the smallest ratio at which one can discriminate two numerical arrays. Performance on this task reveals that most 3-year-old children can accurately identify the larger of the two sets when the ratio between the two arrays is 3:4. Most 6year-old children can identify the larger value when presented with a 5:6 ratio and adults can discriminate 10:11 ratios (Halberda \& Feigenson, 2008). The researchers propose that the development is prolonged throughout childhood and early adulthood because children's numerical acuity becomes more refined with age and experience. In fact, after only 8 hours of practice with tasks that use approximation skills, children showed improved ANS acuity (Halberda \& Feigenson, 2008).

This link between practice and ANS acuity is increasingly important to know and understand given that many researchers argue that the ANS is important for learning other math concepts (e.g., Booth \& Siegler, 2006; Gallistel \& Gelman, 2000) and may even act as a foundation for more advanced understanding of number (Gilmore, McCarthy \& Spelke, 2007). This idea is supported through research showing that children and adults with better ANS acuity tend to have higher math abilities (e.g., Jordan, Glutting \& Ramineni, 2010; Libertus, Feigenson, \& Halberda 2011; Mazzocco, Feigenson \& Halberda, 2011). In fact, even when controlling for age and vocabulary, ANS acuity is strongly related to math achievement (Libertus, Feigenson \& Halberda, 2011). With this in mind, the current study examines this connection between ANS 
acuity and math achievement, and will continue to explore factors that may mediate this relationship.

Knower-Levels. Motivated by Gelman and Gallistel's (1978) seminal research on children's early number concepts, researchers started investigating the developmental trajectory of children's conceptual understanding of number (Carey, 2009; Le Corre \& Carey, 2007; Sarnecka \& Lee, 2009; Wagner \& Walters 1982; Wynn 1990, 1992). One of the central aims of this line of research was to explore how ANS acuity factors into children's developing understanding of number concepts.

Starting in the 1980s and 1990s, research revealed a delay between the time children reliably produce a standard count list and when they develop conceptual knowledge of number (Baroody \& Price, 1983; Carey, 2009; Le Corre \& Carey, 2007; Sarnecka \& Lee, 2009; Wagner \& Walters 1982; Wynn, 1990, 1992; see also Freeman, Antonucci \& Lewis, 2000; Fuson, 1988; Miller, Smith, Zhu, \& Zhang, 1995; Slaughter, Itakura, Kutsuki, \& Siegal, 2011). This work ultimately revealed that children learn to count, and can do so very well, before they build a conceptual understanding of number. So the question becomes, how do children ultimately make this jump from correctly producing the count list to then understanding how each number word represents an exact quantity? One phenomenon that answers this question, and illustrates how children build a conceptual understanding of number, is their predictable progression through a series of "knower-levels."

Interestingly, research on children's early understanding of counting and the positive integer system shows a step-like progression for building a conceptual 
understanding of number (Carey, 2009; Le Corre, Van de Walle, Brannon, \& Carey, 2006). As children gain experience with numbers and number concepts, this knowledge creates a new framework for understanding the entire count list. Children first conceive approximations of number using their number sense (via the ANS) and gradually create exact representations of individual numbers as they learn the number words that make up the count list. Thus, when children initially learn to count, their understanding of quantity does not match the highest number attained on their count list. For example, children may count to 10 without error but may not be able to produce a set of exactly four items when prompted to give "four." This delay from correctly producing the count list to achieving a conceptual knowledge of number (e.g., knowing that the word "six" denotes exactly six items) indicates a need for a more complex explanation of number knowledge development.

Carey (2009) proposed a possible explanation of this phenomenon through a theory of conceptual-role bootstrapping. According to Carey (2009), the count list serves as a placeholder until the conceptual understandings of individual quantities are filled in. To illustrate this account one may look at learning the periodic table of elements. Many of us know just a few elements represented on this table. For example one may know that humans breathe oxygen $\left(0_{2}\right)$ and that calcium $(\mathrm{Ca})$ is in milk and helps build strong bones. The placement of these elements on the periodic table or even the specific symbols that stand for each element may be recognizable, but the names for elements that are encountered less frequently, such as astatine (At) or bromine (Br), may simply serve as a placeholder until more information is filled in. A student studying chemistry will 
then ultimately develop a more sophisticated understanding of these elements helping her to figure out the meaning of each symbol and even the rationale behind the placement of each element on the table. Similar to how we fill in information to the symbols of the periodic table, children seem to fill in the information for number concepts.

One task that illustrates this developmental progression is the Give-A-Number (Give-N) task, first introduced by Wynn $(1990,1992)$. The task proceeds as follows: An experimenter asks a child to put a specific number of items (e.g., "four fish") into a bowl. To determine how many number words the child understands and whether she understands the cardinal principle (CP) of counting (i.e., knowing that the last number recited in a counting routine indicates the numerical quantity of that set) the child is asked to give between "one" and "eight" items. A child who is successful at producing all of these quantities would be considered a Cardinal Principle (or CP-) knower. This is because children who are able to produce quantities between "five" and "eight" must understand that the last number produced in a counting routine indicates the number of items in that set. Children who cannot yet produce larger quantities would be assigned a knower-level depending on the highest quantity the child can produce correctly. For example, a three-knower would be able to correctly produce "one," "two," or "three" items, but this same child would fail to give four objects when prompted to produce "four." Children typically become CP-knowers shortly after they become four-knowers.

Using the Give-N task, Sarnecka and Lee (2009) tested 280 preschool aged children to investigate how children progress through these knower-levels. Their findings support the notion that children develop early number concepts individually and 
sequentially. In other words, children first learn the meaning of the number word "one" and this understanding precedes the conceptual understanding of "two," "three," and "four." Le Corre et al. (2006) coined term "subset knowers" to describe one-, two-, three-, and four-knowers as a group because these children can count to 10 or higher but understand only a subset of the numbers in their count list. These early number words seem to be fundamental to a more advanced understanding of number, but the reason for this remains unknown. One possible explanation stems from research illuminating distinctions children make between small quantities even before they are able to form words (e.g., Feigenson \& Carey, 2005).

In summary, it has been shown that the development of large, exact number concepts is dependent on first acquiring the symbolic placeholders, and then filling in the meanings of these number words (Carey, 2009). This indicates that language, and the ability to communicate through language, plays a key role in the formation of number knowledge. Thus, children's linguistic abilities, among many other important factors, may influence the development of number concepts.

\section{Factors that Influence Foundations}

Language. Confirming the influence of language on the development of exact number concepts, Negen and Sarnecka (2012) found that children with greater general vocabularies tend to use more number words. A possible explanation for this finding is that children who are exposed to more language tend to be exposed to more number words as well. Adding to these findings, Levine, Suriyakham, Rowe, Huttenlocher, and Gunderson (2010) found a robust link between how often parents talk about numbers 
(e.g., using the count list, pointing out a quantity of a set, etc.) during children's first 14 to 30 months to their understanding of the cardinal principle around four years of age. This validates the claim that early experiences influence later developmental trajectories. The connection between general vocabulary and number words (Negen \& Sarnecka, 2012), coupled with the relationship between number language and understanding the cardinal principle (Levine et al., 2010) reveals an intricate relationship between language and the development of number concepts.

Socioeconomic status. The clear influence of language may also pose some explanation as to why socioeconomic status (SES) is seen to influence math abilities (Jordan, Kaplan, Locuniak, \& Ramineni, 2007; Jordan, Kaplan, Oláh, \& Locuniak, 2006; Jordan, Kaplan, Ramineni, \& Locuniak, 2008). Huttenlocher, Vasilyeva, Waterfall, Vevea, and Hedges (2007) looked at parents' child-directed language use in relation to parental education. It was found that parents with higher educational degrees used more words. Additionally, highly educated parents tended to use more complex words and sentences. This is in line with the work of Gunderson and Levine (2011) who found a strong connection between SES (the income a family makes related to their monetary need) and general vocabulary development, suggesting that parents of higher SES tend to talk more with their children. Thus it is clear that socioeconomic factors such as education and income play a role in children's language exposure (see also Hart \& Risley, 2003).

The role of language might then explain the link between SES and math achievement. For example, Jordan and her colleagues (Jordan et al., 2006; Jordan et al., 
2007; Jordan et al., 2008) found that children of low SES families enter school with lower levels of math abilities and develop new math skills at a much slower rate than children of higher SES backgrounds. In fact, it was noted that children of low-income backgrounds are four times more likely to have low math abilities and are less likely to improve on those abilities with formal schooling (Jordan \& Levine, 2009). Although this connection between SES and math abilities is clear, the aforementioned link between general vocabulary and number language in addition to the well-established link between SES and general vocabulary (Gunderson \& Levine, 2011; Hart \& Risley, 2003) suggest that the true cause for this connection is yet to be determined. Therefore, a major aim of this thesis is to explore the connection between SES, general vocabulary, and early math abilities.

\section{Differences in Math Abilities among Young Children}

As mentioned previously, prior to the start of formal education children have established the foundations of more complex mathematical concepts and the relative strength of these foundational skills are predictive of later academic success (Duncan et al., 2007). Nevertheless, children encounter different experiences that may influence how and when these foundational skills develop, and this may result in noticeable differences in math achievement as they enter school. Dowker (2008) was interested in exploring these differences in achievement as children enter formal education. A sample of preschool aged children were assessed for their counting abilities, knowledge of the cardinal principle, knowledge of the order irrelevance principle (the set is the same size regardless of where the counting begins) and their ability to add and subtract one item 
from a given set. Results illustrate considerable variability in what children know as they enter formal education.

Using these findings Dowker (2008) formulated three categories of math abilities. These three classifications included: 1) children who use an "internalized counting sequence" with simple addition and subtraction, 2) children who resort to counting all the objects every time, and 3) children who cannot cope with answering these types of questions. Some children are able to use a sophisticated framework that allows them to understand large quantities and simple addition and subtraction whereas other children refused to answer the more challenging questions. Also, the second category shows that there are some children who rely on counting to determine the answers to challenging questions. These findings reveal that children do not enter school with the same abilities related to math but, importantly, there are many factors essential to the development of a complete understanding of numerical concepts.

\section{The Present Study}

The aims of the this thesis are to: 1) explore the influence of socioeconomic status on the development of early number concepts, 2) investigate the connection between number sense and language, and 3) see if the relationship between SES and general vocabulary (Gunderson \& Levine, 2011; Hart \& Risley, 2003) can explain the link between SES and math achievement (Jordan et al., 2006; Jordan et al., 2007; Jordan et al., 2008). In line with the findings of Gunderson and Levine (2011), which establish a clear link between SES and general vocabulary, coupled with the findings linking general 
vocabulary and number words (Negen and Sarnecka, 2012), similar relationships were expected in the present work. Additionally, it is hypothesized that number sense and general vocabulary will not be related, as this connection has not been revealed in previous research (Libertus, Feigenson, \& Halberda, 2011). The findings of this work will also give insight into the development of number concepts in children while illuminating how socioeconomic factors might influence this path.

\section{Method}

The following recruitment efforts, testing methods, and general procedures were approved and monitored by San José State University's Institutional Review Board.

\section{Participants}

A total of 133 children ranging from $2 \frac{1}{2}$ years to 5 years olds $(M=4$ years $)$ participated in this study. Of these participants, 72 were female and 61 were male. The children were tested in daycare centers or preschools in Middletown, Connecticut ( $n=$ 82), and San José, California $(n=51)$.

\section{Procedures}

Children were invited to play a series of games with an adult experimenter in a designated area in their preschool or childcare center. Sessions started with the Give-aNumber task (Give-N), which was followed by the Who-Has-More task (WHM), and the Peabody Picture Vocabulary Test (PPVT) (see below for task descriptions). After completing these tasks, children were offered a small prize and the parents were given a short survey (see below). 


\section{Instruments}

Parent survey. Parents were provided with a questionnaire to collect additional information about their family. Items on the parent survey asked about family income, education levels of the primary caregivers, sibling information, and personal information about the child including ethnicity, languages spoken in the home, and preschool enrollment.

Give-A-Number (Give-N). The Give-N task (Wynn, 1990, 1992) was used to measure children's understanding of individual number words and their understanding of the cardinal principle of counting. To begin a row of 20 toy fish were lined up and the child was asked to count each fish. It was noted if 10 fish were counted and if any numbers were missed while counting to 20 . Then, the child was prompted to put different quantities of fish into a fishbowl to determine how many number words she understands. The child was given opportunities to fix the quantity if she recognized an error.

Who-Has-More (WHM). The Who-Has-More (WHM) task measures children's number sense. In this task the child was shown two arrays of dots on a 15-inch laptop computer screen. One side of the screen displayed a set of blue dots and the other displayed a set of yellow dots. The experimenter said, "Here are the yellow dots; here are the blue dots. Which side has more?" The child was instructed to point to one side of the screen or push a blue or yellow button on the keyboard. If the child did not pick the larger set a buzzer sound played and the experimenter informed him that his answer was incorrect. The experimenter then encouraged him to try again by saying something to the 
effect of "Oops! That's ok, let's try another one." If the child selected the larger dot array then a chime played and the experimenter reaffirmed that he was correct. There were six practice trials where each array was shown individually (first the yellow dots, then the blue dots) and then the dot arrays were shown side-by-side on the screen. The practice trials gave children two opportunities to see the dots before they had to select a side. Following the six practice trials, the 58 recorded trials began. For the 58 trials, the child was shown both yellow and blue dots on a screen for a short period of time before they disappeared. The child was asked, "Which side has more dots?" Different from the practice trials, the child was able to see the arrays only once, side-by-side. For both the practice and recorded trials, the ratios of the yellow and blue dots varied to measure ANS acuity. For example, some trials displayed smaller ratios (such as one yellow dot for every two blue dots), whereas other trials presented more difficult ratios (such as 10 yellow dots for every 11 blue dots).

Peabody Picture Vocabulary Test (PPVT). The Peabody Picture Vocabulary Test (PPVT), $4^{\text {th }}$ ed., adapted from L. M. Dunn and D. M. Dunn (2007), is a standardized test of general vocabulary. A child was shown a page with four pictures on it and was asked to point to the picture associated with a given word. For example, a child was shown the page with a picture of a pear, a red ball, grapes, and an apple and was asked, "Can you point to the apple?" Each question was a part of a 12 question set. The task ended when a child got eight or more items within the set incorrect. 


\section{Data Analysis}

Parent survey. Of particular interest for this study was information about family income, parent education, and the primary caregivers for the children in the study. Information from the survey was also used to calculate income-to-needs ratios - a measure of SES. This was calculated using the mean of the reported income range divided by the poverty threshold as provided by the US Census Bureau (2012). An income-to-needs ratio of one indicates the family is living on the poverty threshold.

Give-A-Number (Give-N). Data from the Give-N task was used to determine participants' knower-levels. Based on the largest set the child could quantify, each child was assigned a knower-level (one-, two-, three-, four-, or CP-knower). A one-knower can consistently produce sets of one item when asked for "one." A four-knower, on the other hand, can accurately produce sets associated with the number words "one" through "four." A CP-knower understands the cardinal principle and can therefore use counting to produce the correct number of items associated with any number words assessed through this task.

Who-Has-More (WHM). For each child, the percent of correct responses on the dot discrimination task was calculated. This score was used as a measure of ANS acuity, as this task identifies one's ability to discriminate sets across various ratios.

Peabody Picture Vocabulary Test (PPVT). A norm-referenced score was generated for analysis. The raw score compared the number of items answered correctly to the number of items answered incorrectly. This score was then compared to the age of the child at the time of the test to generate a standardized score. 


\section{Results}

\section{Relationships Within Tasks}

Parent Survey. Out of the 133 participants, 62 families completed the survey. The children of these families ranged in between 2 years, 7 months and 5 years of age ( $M=3$ years 11 months). Less than $1 \%$ of the families indicated that their child did not attend preschool. Eight-five percent of the children had at least one sibling. The sample was fairly evenly distributed across income levels (Figure 1A). Looking at education, most of the parents from the sample had earned at least a bachelor's degree, and a very large portion of these families held master's or doctorate degrees (Figure 1B). The majority of the sample was White/European American (41\%). There was also a large portion of Latino (22\%) children. Only 5\% reported being Asian American and less than 2\% reported being African American. A large portion of the sample reported mixed or other races (19\% and $7 \%$, respectively).

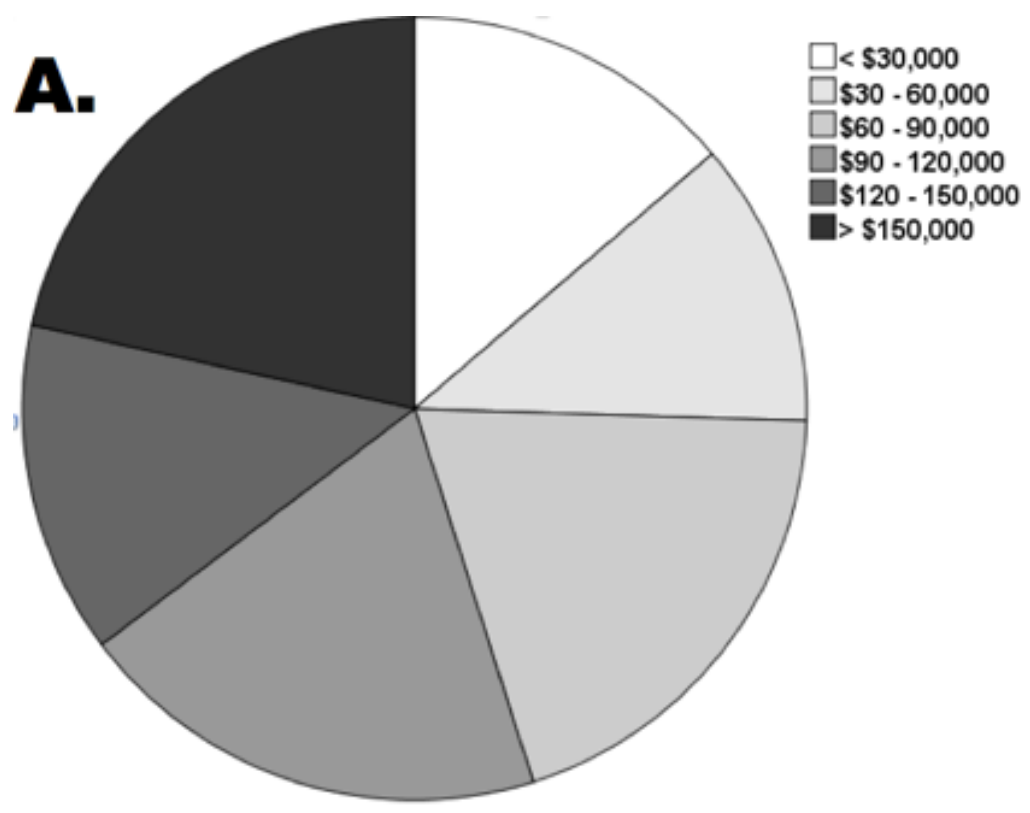




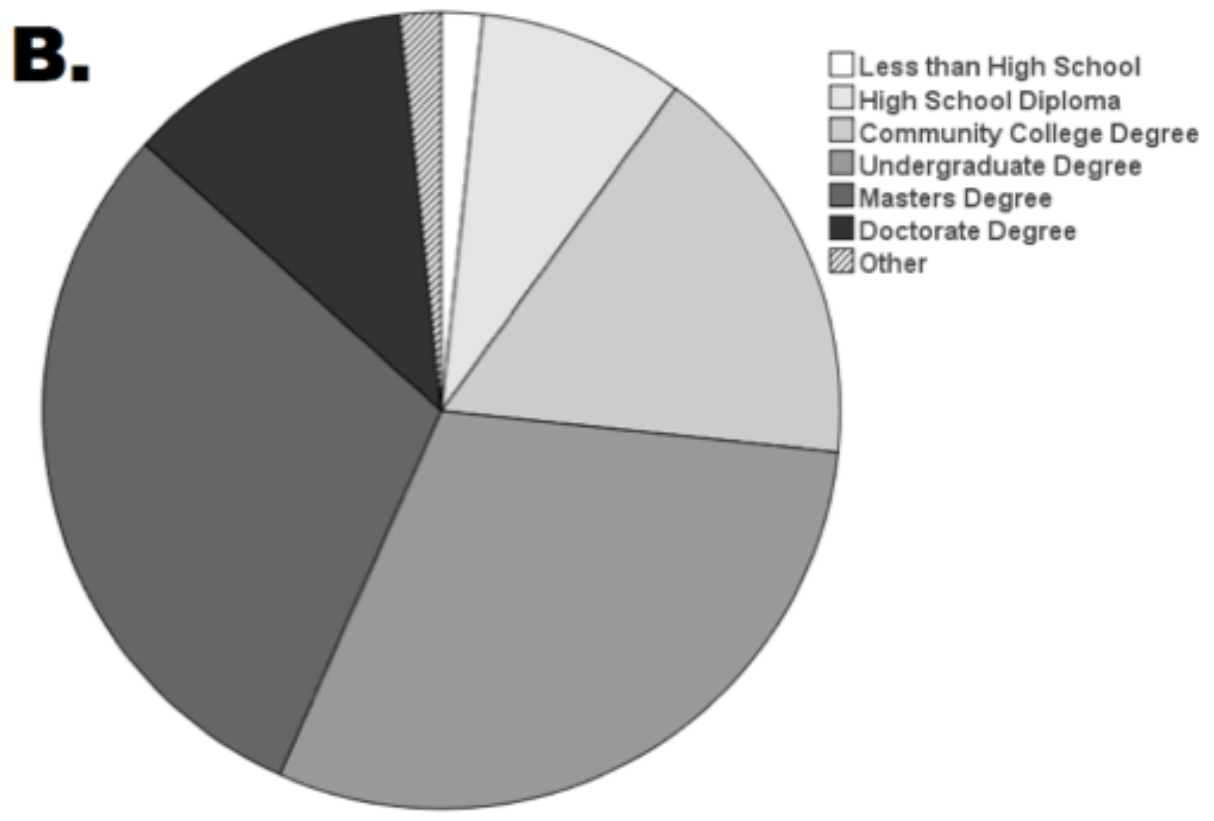

Figure 1. Distribution of family income (Figure 1A) and education (Figure 1B) across participant sample.

Give-A-Number (Give-N). Of the 133 participants, a total of 131 participants completed the Give-N task, with ages ranging from 2 years, 6 months to 5 years old ( $M=4$ years). There were eight pre-knowers, 15 one-knowers, 23 two-knowers, 17 three-knowers, 15 four-knowers, and $53 \mathrm{CP}$-knowers (Figure 2). An analysis of variance (ANOVA) evaluating children's age and number word knowledge (as measured by the Give-N task) showed a systematic increase of knower-level concurrent with age $F(5,125)=6.73, p<.01$. That is to say, as children get older their understanding of individual number words increases. A Mann-Whitney U-Test evaluating the potential interaction of number word knowledge and sex revealed no significant difference across the sexes, $U(130)=1.25, p=.21$. 


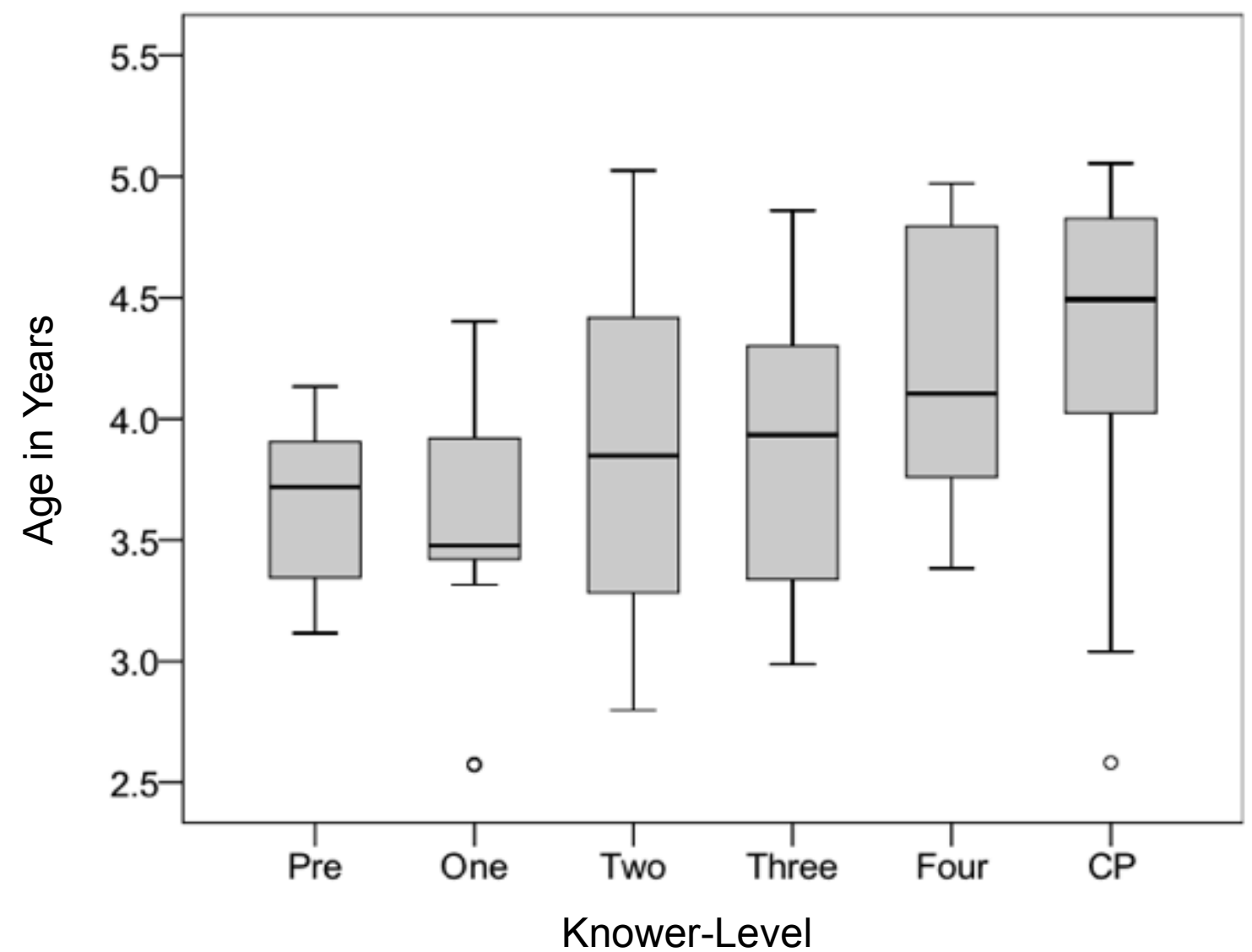

Figure 2. Children's number word knowledge (i.e., knower-level, determined through the Give-N task) systematically increases with age. The dark horizontal lines indicate the median age of each group, the shaded boxes indicate the $1^{\text {st }}$ and $3^{\text {rd }}$ quartiles, and the vertical lines represent the minimum and maximum values (excluding outliers).

Who-Has-More (WHM). Of the 133 participants, 125 children completed the WHM task. These children ranged in age from 2 years, 6 months to 5 years old $(M=4$ years, 1 month). Results revealed a significant correlation between performance on the WHM task and age, $r(125)=.39, p<.01$ (Figure 3). That is to say, as children get older their number sense acuity improves. 


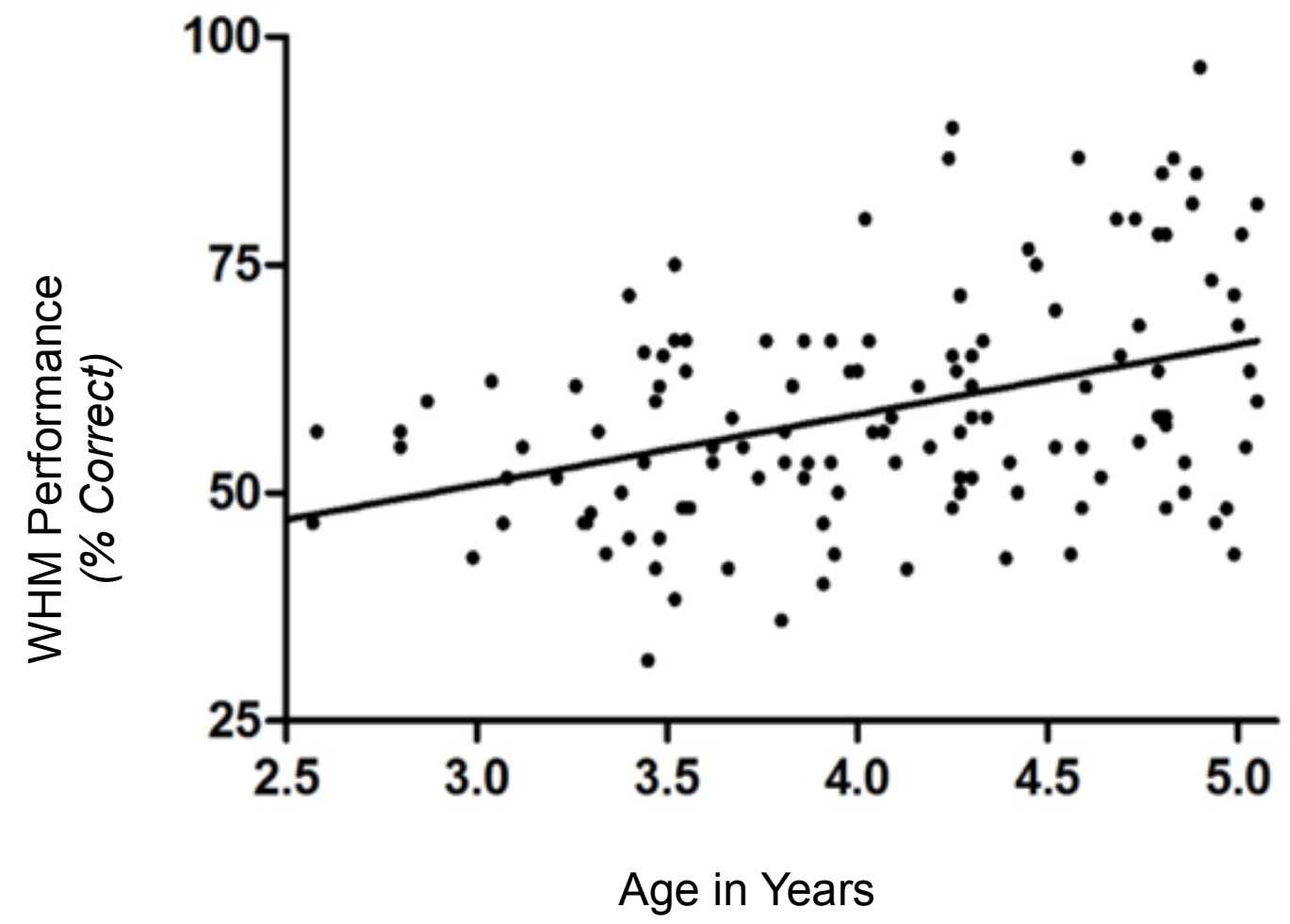

Figure 3. Children's numerical acuity (as measured by their performance on the WHM task) systematically increases with age.

Peabody Picture Vocabulary Test (PPVT). Of the 133 participants, a total of 127 children completed the PPVT, with ages ranging from 2 years, 6 months to 5 years old ( $M=4$ years, 1 month). The distribution of standard scores within the sample approximated a normal distribution $(M=105.02, S D=16.89)($ Figure 4$)$. An independent samples t-test revealed no significant difference between the sexes for performance on the PPVT, $t(125)=.51, p=.62$. 


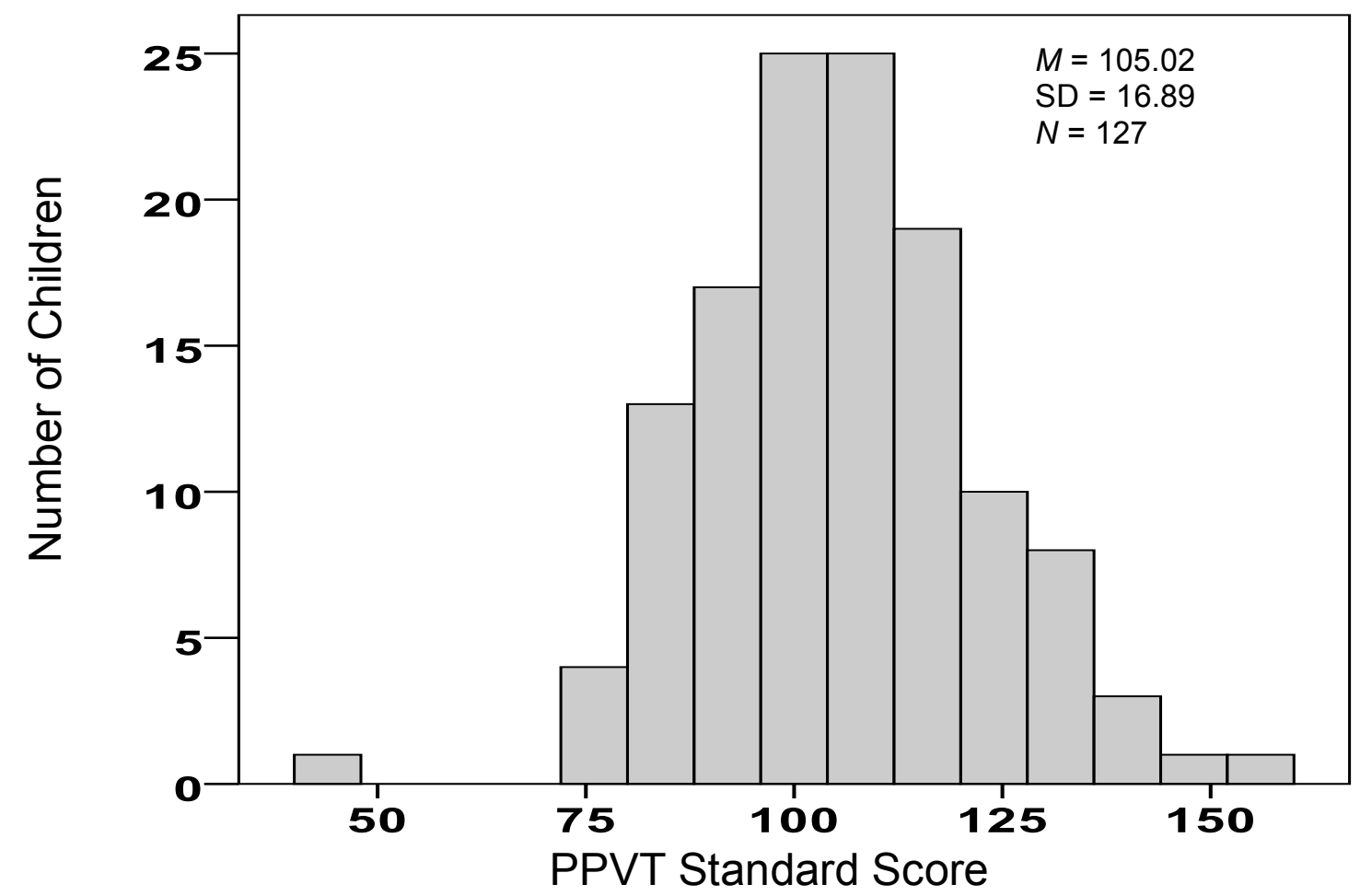

Figure 4. Children's general vocabulary (as measured by the PPVT) approximates a normal distribution.

\section{Relationships Between Tasks}

Give-A-Number and Who-Has-More. Of the 133 participants, 123 completed both the Give-N task and the WHM task. An analysis of variance (ANOVA) revealed a difference in WHM performance across the various knower-levels, $F(5,117)=11.17, p<$ .01. This is to the effect that children performing well on the WHM task tended to be classified in higher knower-levels (Figure 5). In fact, Tukey's B pairwise comparisons indicate that children in the CP-knower level perform significantly better on the WHM task compared to children in each of the subset knower-levels $(p s<.05)$. 


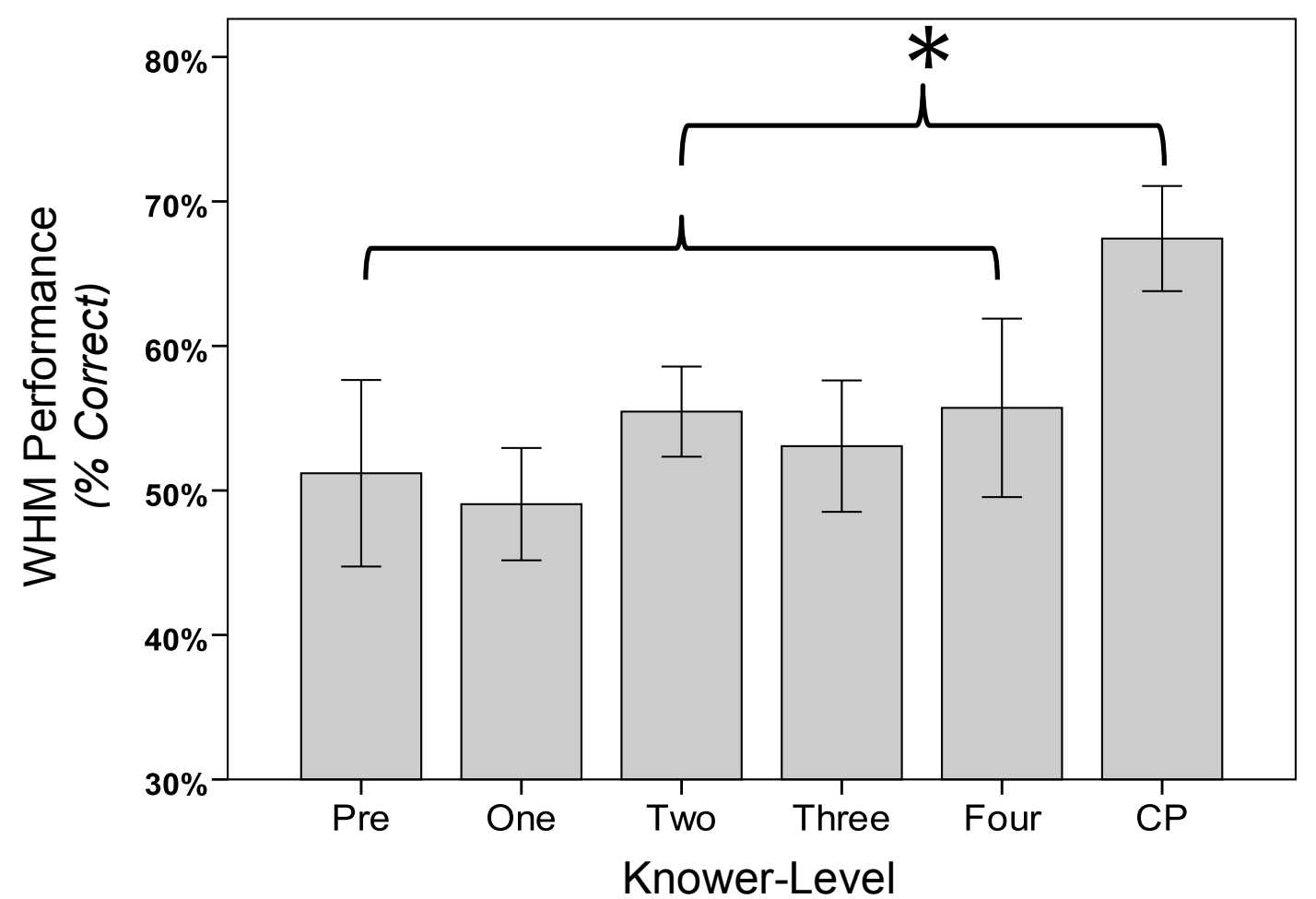

Figure 5. Children's numerical acuity (performance on the WHM task) is systematically related to their number word knowledge (knower-level). Asterisks indicate a significant $(p<.05)$ difference across groups.

Give-A-Number and Peabody Picture Vocabulary Test. Of the sample, 126 participants completed both the Give-N task and the PPVT task. It was found that children's general vocabulary, as measured by their performance on the PPVT, was systematically related to their knower-level, $F(5,120)=4.94, p<.01$. That is to say, children with larger general vocabularies also tended to have greater number word knowledge, as demonstrated by their performance on the Give-N task (Figure 6).

Tukey's B pairwise comparisons revealed that pre-knowers drove this significant result, 
as pre-knowers' performance on the PPVT was significantly lower than children in other knower-levels.

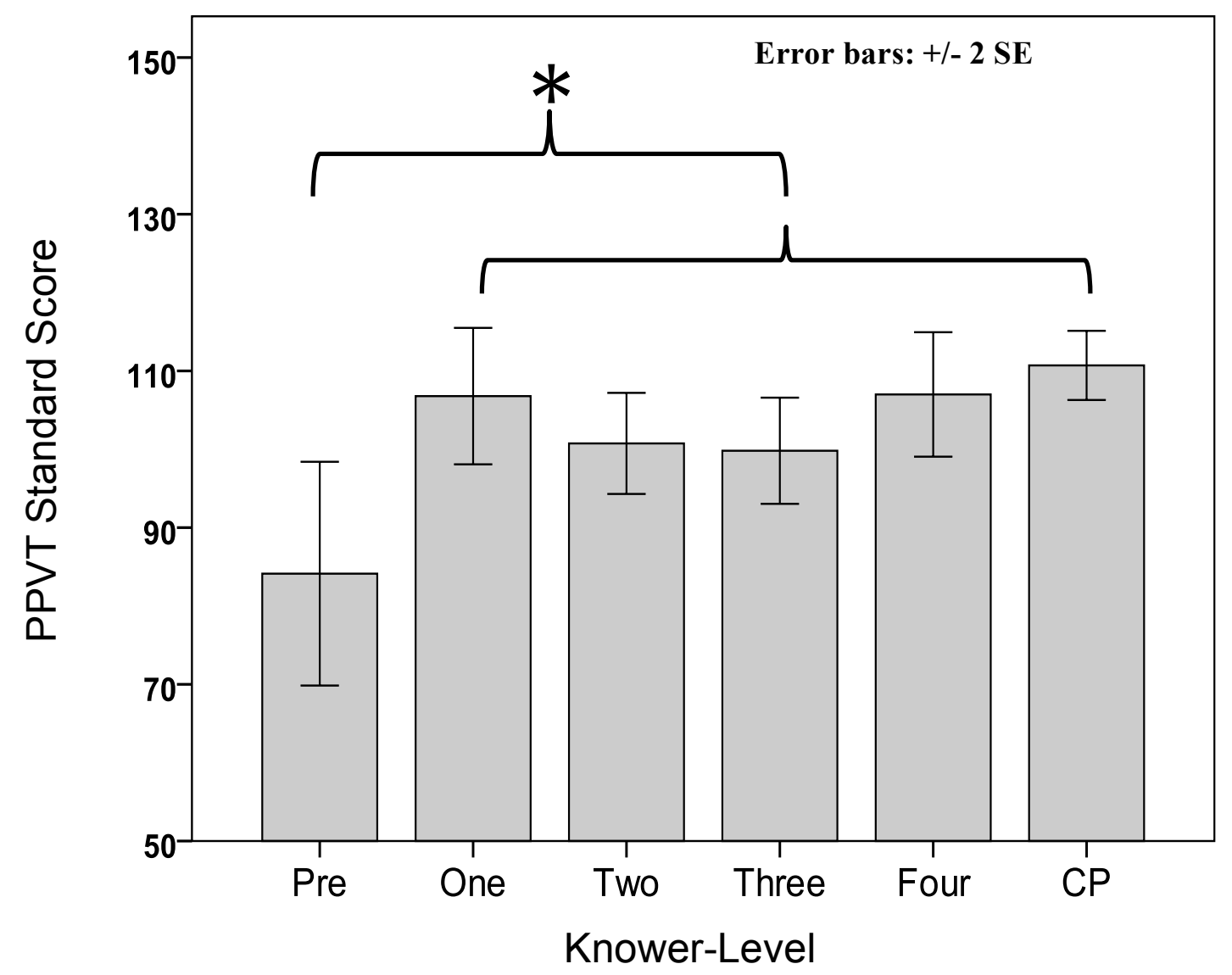

Figure 6. Children's general vocabulary (PPVT score) is systematically related to their number word knowledge (knower-level). Asterisks indicate a significant $(p<.05)$ difference across groups.

Who-Has-More and Peabody Picture Vocabulary Test. Out of the 133 participants, 120 children completed both the WHM and PPVT tasks. Analyses revealed 
a positive correlation between children's number sense, as measured by performance on the WHM task, and general vocabulary, as measured by performance on PPVT, $r(120)=$ $0.33, p<.01$ (Figure 7). Therefore, children with greater general vocabularies also tended to have a more refined number sense.

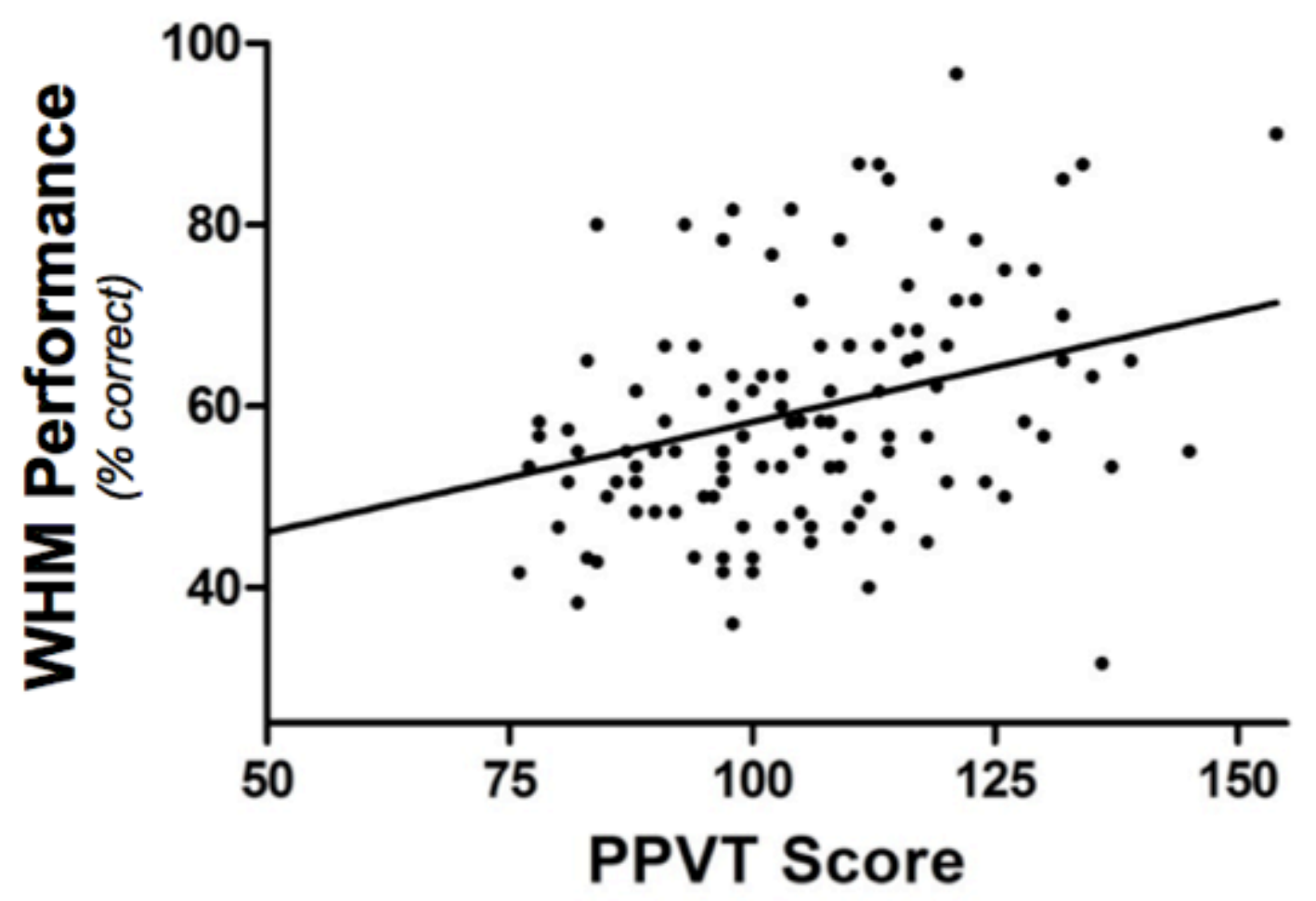

Figure 7. Children's numerical acuity (performance on the WHM task) is systematically related to their general vocabulary (PPVT score).

\section{Influence of Family Income (income-to-needs ratio)}

Income and Give-A-Number. From the sample, 52 participants completed the Give-N task and also gave information for income. There was no notable relationship 
between children's number word knowledge (knower-level) and their income-to-needs ratio, $F(4,47)=1.12, p=.36$ (Figure 8 ). For this sample, income did not influence number language.

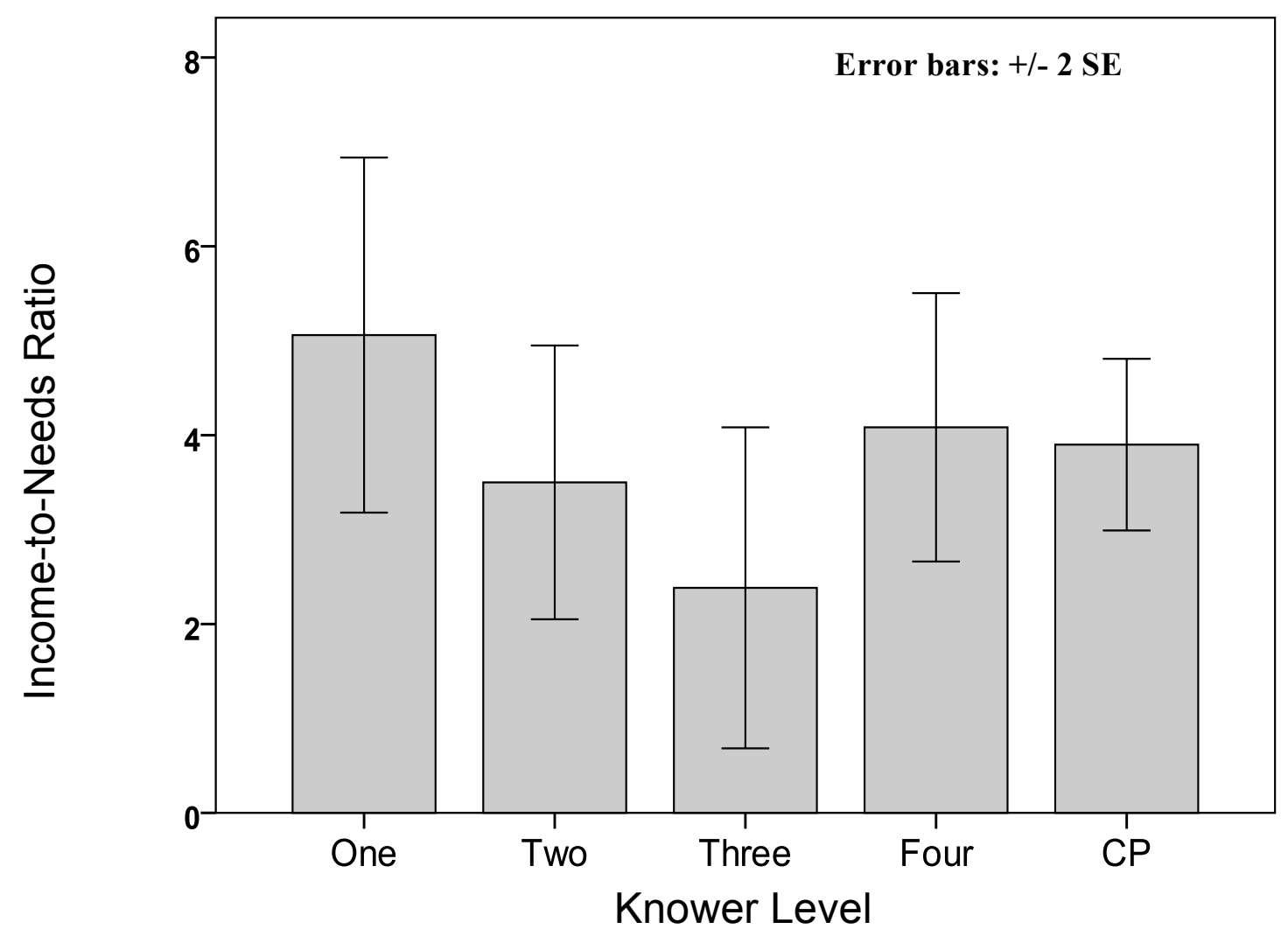

Figure 8. Socioeconomic status in not systematically related to children's number word knowledge (as measured by the Give-N task).

Income and Who-Has-More. Of the 133 participants, 49 participants provided data for both WHM and income. Analyses revealed that SES is not significantly correlated to children's number sense, as measured by their performance on the WHM 
task, $r(49)=-.03, p>.80$ (Figure 9). Therefore, income did not appear to influence number sense in children.

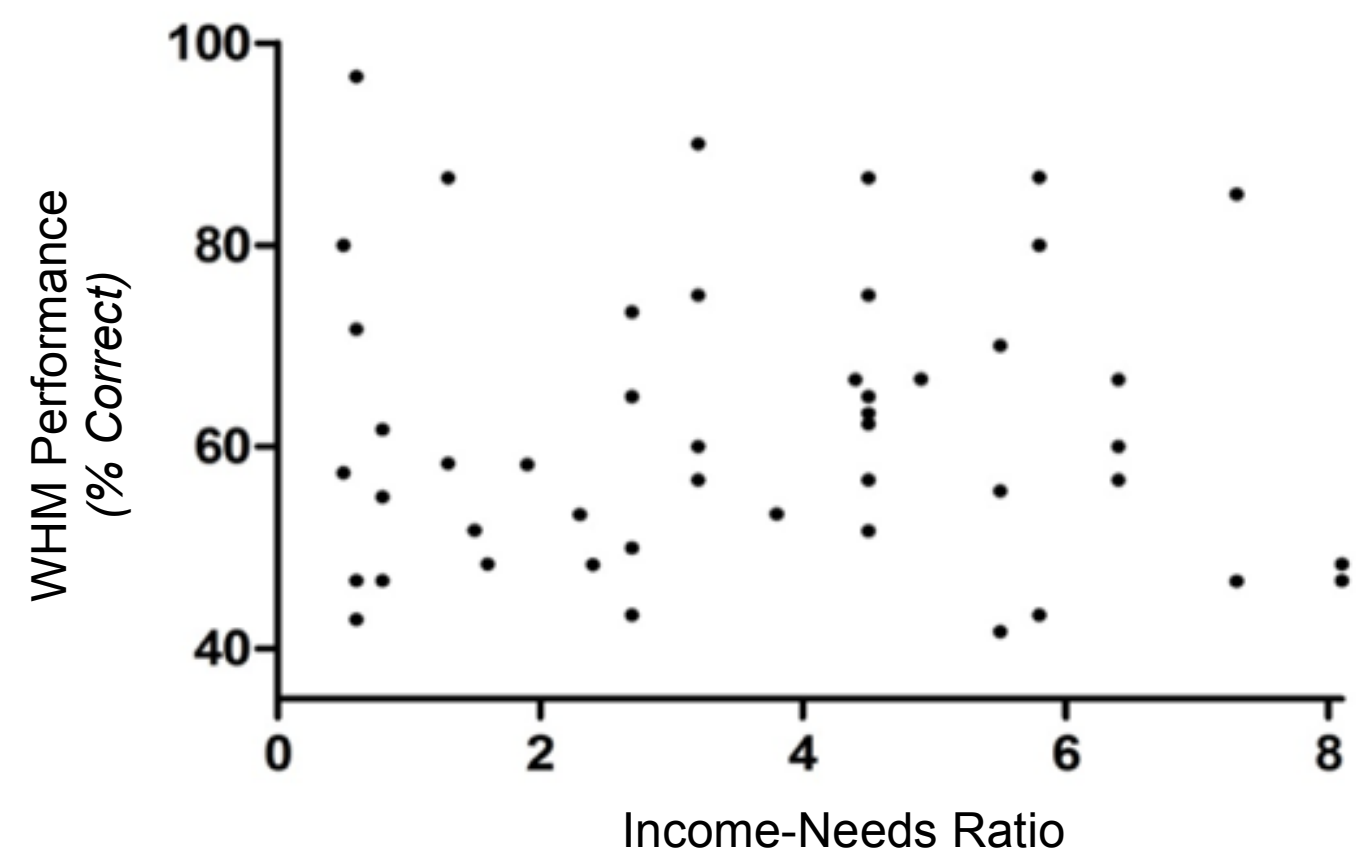

Figure 9. Socioeconomic status is not systematically related to children's numerical acuity (as measured by the WHM task).

Income and Peabody Picture Vocabulary Test. Of the 133 participants, 48 children provided information for income and PPVT. No correlation was initially detected between SES and children's general vocabulary (as measured by PPVT), $r(48)=.21, p=.15$. However, income was found to have an influence on children's general vocabulary, especially for low-income families. Further analysis using a segmented linear regression test revealed that there was a strong relationship between these two factors in the sample of low-income children, $r(23)=.48, p=.02$; a 
relationship that apparently did not exist in the sample of high-income children, $r(25)=-.38, p=.06($ Figure 10$)$

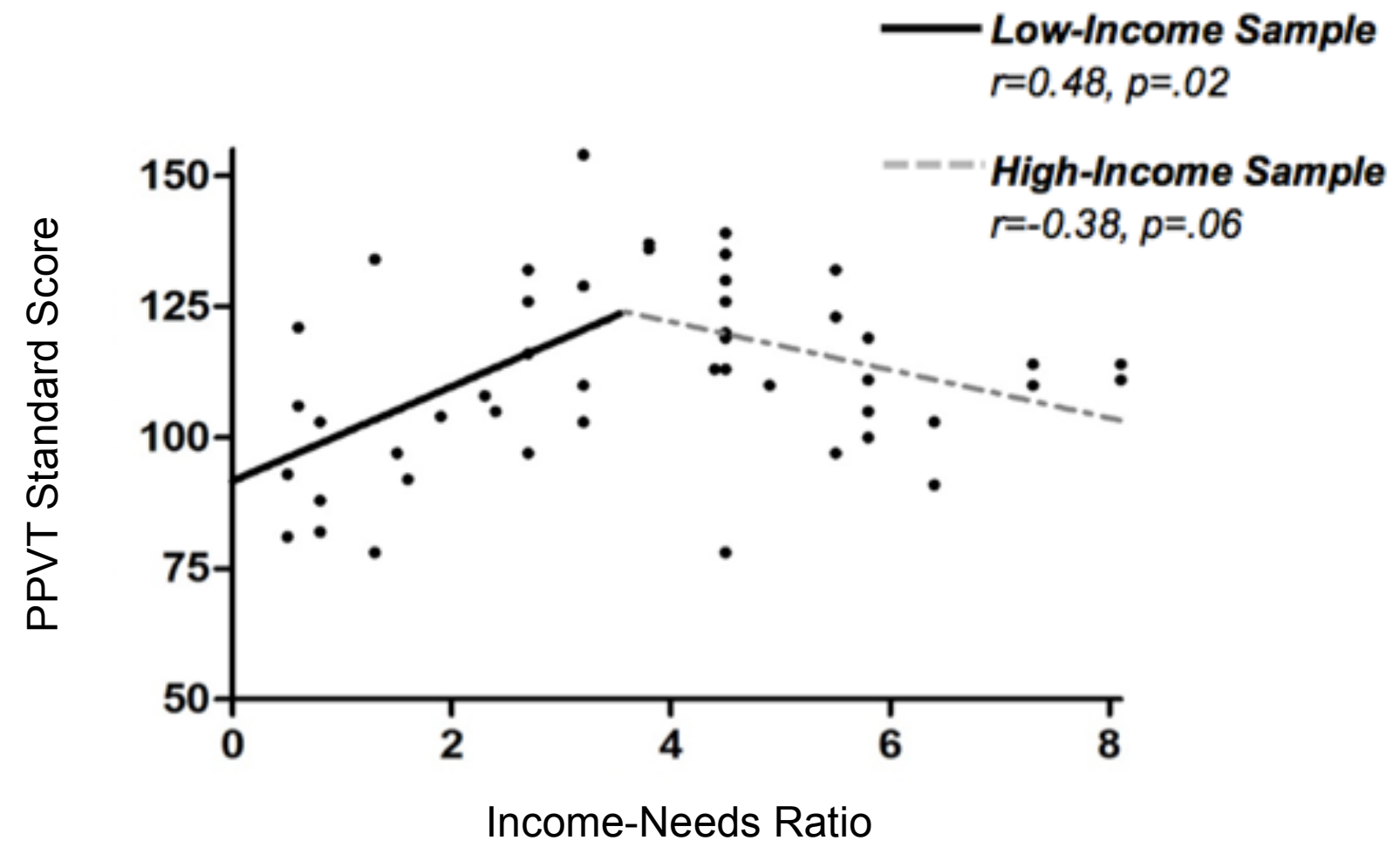

Figure 10. Socioeconomic status is systematically related to children's performance on their general vocabulary skills (as measured by the PPVT task).

\section{Discussion}

Children's number word knowledge (i.e., knower-level) is shown to systematically increase with age. This finding aligns with previous research that shows a step-like progression through the knower-levels (Carey, 2009; Le Corre et al., 2006). The progression through each knower-level takes time, as young children may stay in a knower-level for months or even a year before they are able to quantify the number 
associated with the following knower-level. Furthermore, young children do not develop a complete understanding of the cardinal principle until around their fourth birthday, indicating a need for greater cognitive processes to acquire a conceptual understanding of number.

Clearly then, as children get older, they gain a greater understanding of numbers and counting, but how much of this influence is due to the greater cognitive processes that come with age and how much is actually from children's experiences related to math? Previous research has found that certain principles, such as ANS acuity and the ability to correctly produce a standard count list, are influenced by practice (Baroody \& Price, 1983; Dowker, 2008; Halberda \& Feigenson, 2008). Therefore, it is reasonable to assume that as children get older they are also exposed to more practice with tasks that increase their understanding of number. This notion is supported by the relatively large age range $\left(2 \frac{1}{2}-5\right.$ years old) included in each knower-level, suggesting that while age is related to children's number word knowledge, experience may also play a large role.

Analyses also reveal a significant, positive relationship between children's number sense and age. These results are in line with Halberda and Feigenson's (2008) work, which shows that as children get older their numerical acuity increases. This could be due to increased cognitive processes that come with getting older or from experiencing tasks that require approximation and estimation. Children who may not practice at home or do not have much experience with number concepts would ultimately be exposed to these things in school. Quite possibly just having experience with numbers and math concepts such as addition in school may help children refine their numerical acuity. 
Importantly, children's understanding of number words, as demonstrated through their knower-level, is related to both their general vocabulary and number sense. Previous research has found that general vocabulary is linked to number words and shows that children with greater general vocabularies also know more number words (Negen \& Sarnecka, 2012). Furthermore, it seems this relationship is unidirectional, with general vocabulary being predictive of number language. This reveals the importance of general vocabulary for the development of number concepts. As previously discussed, children must understand the meaning of individual number words before they can represent exact number concepts, which is demonstrated by their progression through the knower-levels only after the number words for the count list are obtained. Interestingly, number language is also related to children's number sense. This is in line with previous research linking children's ability to understand the count list, number words, and the cardinal principle to their number sense (Wagner \& Johnson, 2011). The link between general vocabulary and number words coupled with the relationship between number words and number sense then illustrates the influence of language on the development of math concepts.

An aim of this study was to explore the relationship between children's number sense and later math abilities by looking at the influence of language, more specifically number words, as a mediating factor between number sense and math abilities. A relationship between number sense and number language was revealed, giving weight to the claims that number sense is important for understanding other math and number concepts (Booth \& Siegler, 2006; Gallistel \& Gelman, 2000). Number sense was also 
related to children's general vocabulary. This result was not expected as previous research has yet to identify a strong link between number sense and general vocabulary (Libertus, Feigenson \& Halberda, 2011). Looking at the relationship between general vocabulary and number language, coupled with the link between number language and number sense, it seems number language acts as the mediating factor between these two variables.

In a diverse group of participants of preschool aged children and their families, findings revealed no significant relationships between income and number language, as measured by the Give-N task, nor between income and number sense, as measured by the Who-Has-More (WHM) task. However, income is related to general vocabulary, and this result holds especially true for low-income families. Results also reveal a positive relationship between general vocabulary and number language. Therefore the connection between SES and math achievement (Jordan et al., 2006; Jordan et al., 2007; Jordan et al., 2008) needs a more complex explanation that includes factors such as a children's general vocabulary, number language, and number sense.

Another aim of this study was to investigate the influence of socioeconomic status on the development of children's early number concepts specifically to determine if general vocabulary mediates the link between SES and math achievement, and results indicated that this indeed was the case. The exploration of the influence of language on the relationship between number sense and math abilities revealed mixed results calling for further investigation and further research that controls for number language when comparing general vocabulary and number sense. One final result revealed from this 
work is that environmental factors, such as family income, influence the way children learn and understand number concepts.

In conclusion, results of this study confirmed the influence of SES on children's number concepts through the relationship between family income and children's general vocabulary. In general, many variables play a role in the development of children's early number concepts, SES being one of the major contenders given the clear relationship with general vocabulary. Therefore, once children are in school, educators must take into account different SES backgrounds, specifically for low-income children, and the influence SES has on vocabulary development. This will allow educators to better understand variability in children's abilities and help children who are struggling with math.

A major strength of this study is the large sample size, with over 100 participants, as well as the diversity of the sample related to SES. Another strength of this study is the validity of measures. The Give-N task, WHM task, and PPVT have been found to be very reliable measures for assessing cognitive and language development of young children (e.g., Negen \& Sarnecka, 2012; Sarnecka \& Lee, 2009). Finally, this work contributes to a growing body of research looking into the development of early number concepts in children and the influence of SES.

Some limitations of the study included the duration of entire testing session as each task (Give-N, WHM, and PPVT) took on average 10 minutes to complete. Therefore, children were expected to sit one-on-one with the examiner for this entire 30 minute time period. Sitting and being tested for this extended amount of time may 
influence the results as children may have been distracted or bored with the tasks. To minimize this effect, children were offered "sticker breaks" throughout the data collection period to keep them focused on the task. Also, some of the testing locations were secluded in a separate room, whereas others were not. When the data were collected in an area where the other children in the preschool could see and interact with the examiner, there were frequent interruptions by other children, which contributed to distractions for the participants.

Since this study was cross-sectional by design, long-term influences of SES and the developmental trajectory of children's early number concepts could not be assessed. A longitudinal study design would allow for a more complete picture of the development of number concepts as well as the long-term influence of SES on math abilities in later childhood. In that case, future research should look into the projected relationship between number language and math achievement to further evaluate the link between SES and math achievement.

One final factor worth considering, which has been receiving a lot of attention in recent literature, is the role of executive functioning. Executive functioning supports children's attention span, their memory, and their ability to retain information. In addition to SES and language, future research should investigate the role of executive functioning as a contributing factor to the development of number concepts. Additionally, the different experiences children encounter related to these variables should be explored in hopes to understand the variability of math abilities in children as they enter school. 


\section{References}

Baroody, A. J. \& Price, J. (1983). The development of the number-word sequence in the counting of three-year-olds. Journal for Research in Mathematics Education, 14, 361-368.

Booth, J. L., \& Siegler, R. S. (2006). Developmental and individual differences in pure numerical estimation. Developmental Psychology, 42(1), 189-201. doi: 10.1037/0012-1649.41.6.189

Carey, S. (2009). The Origin of Concepts. New York: Oxford University Press.

Dehaene, S. (1997). The Number Sense: How the Mind Creates Mathematics. New York: Oxford University Press.

Dowker, A. (2008). Individual differences in numerical abilities in preschoolers. Developmental Science, 11, 650-654.

Duncan, G. J., Dowsett, C. J., Claessens, A., Magnuson, K., Huston, A. C., Klebanov, P., \& ... Japel, C. (2007). School readiness and later achievement. Developmental Psychology, 43, 1428-1446. doi:10.1037/0012-1649.436.1428

Dunn, L. M., \& Dunn, D. M. (1997). Peabody Picture Vocabulary Test III. New York: American Guidance Service.

Feigenson. L. \& Carey, S. (2005). On the limits of infants' quantification of small object arrays. Cognition, 97, 295-313.

Freeman, N. H., Antonucci, C. \& Lewis, C. (2000). Representation of the cardinality principle: Early conception of error in a counterfactual test. Cognition, 74, 71-89. 
Fuson, K. C. (1988). Children's Counting and Concepts of Number. New York: SpringerVerlag Publishing.

Gallistel, C. R., \& Gelman, R. (2000). Non-verbal numerical cognition: From reals to integers. Trends In Cognitive Sciences, 4(2), 59-65. doi:10.1016/ S1364-6613(99)01424-2

Gelman, R. \& Gallistel, C. R. (1978). The Child's Understanding of Number. Cambridge: Harvard University Press.

Gilmore, C. K., McCarthy, S. E., \& Spelke, E. S. (2007). Symbolic arithmetic knowledge without instruction. Nature, 447(7144), 589-591. doi:10.1038/nature05850

Gunderson, E. A. \& Levine, S. C. (2011). Some types of parent number talk count more than others: Relation between parents' input and children's number knowledge. Developmental Science, 14, 1021-1032.

Hart, B., \& Risley, T. R. (2003). The Early Catastrophe. The 30 Million Word Gap. American Educator, 27(1), 4-9.

Halberda, J., \& Feigenson, L. (2008). Developmental change in the acuity of the 'number sense': The approximate number system in 3-, 4-, 5-, and 6-year-olds and adults. Developmental Psychology, 44(5), 1457-1465. doi:10.1037/a0012682

Huttenlocher, J., Vasilyeva, M., Waterfall, H. R., Vevea, J. L., \& Hedges, L. V. (2007). The varieties of speech to young children. Developmental Psychology, 43(5), 1062-1083. doi:10.1037/0012-1649.43.5.1062 
Jordan, N. C., Kaplan, D., Oláh, L., \& Locuniak, M. N. (2006). Number sense growth in kindergarten: A longitudinal investigation of children at risk for mathematics difficulties. Child Development, 77(1), 153-175. doi:10.1111/j. 1467-8624.2006.00862.x

Jordan, N. C., Kaplan, D., Locuniak, M. N., \& Ramineni, C. (2007). Predicting firstgrade math achievement from developmental number sense trajectories. Learning Disabilities Research \& Practice (Wiley-Blackwell), 22(1), 36-46. doi:10.1111/j. 1540-5826.2007.00229.x

Jordan, N. C., Kaplan, D., Ramineni, C., \& Locuniak, M. N. (2008). Development of number combination skill in the early school years: When do fingers help?. Developmental Science, 11(5), 662-668. doi:10.1111/j.1467-7687.2008.00715.x Jordan, N. C., Glutting, J., \& Ramineni, C. (2010). The importance of number sense to mathematics achievement in first and third grades. Learning \& Individual Differences, 20(2), 82-88.

Jordan, N. C. \& Levine, S. C. (2009). Socioeconomic variation, number competence, and mathematics learning difficulties in young children. Developmental Disabilities Research Reviews, 15, 60-68.

Le Corre, M. \& Carey, S. (2007). One, two, three, four, nothing more: An investigation of the conceptual sources of the verbal counting principles. Cognition, 105, 395438. 
Le Corre, M., Van de Walle, G., Brannon, E. M., \& Carey, S. (2006). Re-visiting the competence/performance debate in the acquisition of the counting principles. Cognitive Psychology, 52, 130-169.

Levine, S. C., Suriyakham, L., Rowe, M., Huttenlocher, J., \& Gunderson, E. A. (2011b). What counts in the development of children's number knowledge? Developmental Psychology, 46, 1309-1313.

Libertus, M. E., Feigenson, L., \& Halberda, J. (2011). Preschool acuity of the approximate number system correlates with school math ability. Developmental Science, 14(6), 1292-1300. doi:10.1111/j.1467-7687.2011.01080.x

Miller, K. F., Smith, C. M., Zhu, J., \& Zhang, H. (1995). Preschool origins of crossnational differences in mathematical competence: The role of number-naming systems. Psychological Science, 6, 56-60.

Mazzocco, M. M., Feigenson, L., \& Halberda, J. (2011). Preschoolers' precision of the Approximate Number System predicts later school mathematics performance. Plos ONE, 6(9), doi:10.1371/journal.pone.0023749

Negen, J., \& Sarnecka, B. W. (2012). Number-concept acquisition and general vocabulary development. Child Development, 83(6), 2019-2027. doi:10.1111/j. 1467-8624.2012.01815.x

Romano, E., Babchishin, L., Pagani, L. S., \& Kohen, D. (2010). School readiness and later achievement: Replication and extension using a nationwide Canadian survey. Developmental Psychology, 46(5), 995-1007. doi:10.1037/a0018880 
Sarnecka, B. W. \& Lee, M. D. (2009). Levels of number knowledge during early childhood. Journal of Experimental Child Psychology, 103, 325-337.

Slaughter, V., Itakura, S., Kutsuki, A., \& Siegal, M. (2011). Learning to count begins in infancy: Evidence from 18 month olds' visual preferences. Proceedings of the Royal Society Biological Sciences, [Online] 16 Feb. doi: 10.1098/rspb.2010.2602

U.S. Census Beureu (2012) Poverty thresholds. Retrieved from https://www.census.gov/ hhes/www/poverty/data/threshld/

Wagner, S. H. \& Walters, J. (1982). A longitudinal analysis of early number concepts: From numbers to number. In G. Forman (ed.), Action and Thought: From Sensorimotor Schemes to Symbolic Operations. New York: Academic Press, 137-161.

Wynn, K. (1990). Children's understanding of counting. Cognition, 36, 155-193.

Wynn, K. (1992). Children's acquisition of the number words and the counting system. Cognitive Psychology, 24, 220-251. 